\title{
Um Qlhar Geográfico Sobre a Identidade Grapiúna: A Identidade das Terras do Sem Fim de Jorge Amado
}

\section{A Geographic Look at the Grapiúna Identity: The Identity of Terras do Sem Fim of Jorge Amado}

\author{
Rita de Cássia Evangelista dos Santos*
}

Valéria Cristina Pereira da Silva**

\begin{abstract}
Resumo:
O artigo busca no romance Terras do Sem Fim elementos que, segundo Jorge Amado, são característicos da identidade grapiúna, a identidade da região cacaueira da Bahia. Ao narrar as disputas por terras para o plantio do cacau, no sul da Bahia, no final do século XIX e início do século XX, Jorge Amado nos fornece muitas características dessa região, onde, a partir do intenso processo migratório, mesclaram-se diferentes sujeitos sociais com seus costumes, crenças, experiências, vivências, hábitos conformando assim uma região cultural com identidade própria tendo o cacau como o grande símbolo. Como metodologia, utilizamos a pesquisa bibliográfica a partir da análise do romance em questão embasando-a com textos de importantes autores que estudam o tema da identidade. O livro "O que faz ser nordestino" de Maura Penna (1992) foi utilizado enquanto recurso metodológico, sendo correlacionadas as hipóteses que a autora levanta sobre as características dos nordestinos com algumas partes do romance em que Jorge Amado apresenta-nos alguns aspectos da identidade grapiúna, afim de melhor compreender as nuances desta identidade.
\end{abstract}

\begin{abstract}
:
This article searches in the novel Terras do Sem Fim elements that, according to Jorge Amado, are typical features of the grapiúna identity, the cocoa region of Bahia. By narrating the disputes over lands for the planting of cocoa, in the south region of Bahia, in the late nineteenth and early twentieth century, Jorge Amado provides us with many characteristics about this region where as a result of the intense migratory process, different social subjects with their customs, beliefs, experiences, habits which resulted in a cultural region with its own identity and having cocoa as the great symbol. The bibliographical research was used as methodology, based it on texts written by important authors who have studied the theme of identity. The book "O que faz ser nordestino" by Maura Penna (1992) was used as a methodological resource, and the hypotheses that the author points out about the characteristics of the Northeast people were correlated with the ideas of the novel in which Jorge Amado presents some aspects of the identity of grapiúna in order to better understand the nuances of this identity.
\end{abstract}

* Mestranda do PPGeo UFG. Professora do Instituto Federal de Ciência e Tecnologia da Bahia.

** Doutora em Geografia. Professora do Programa de Pós-graduação em Geografia da UFG
Palavras-chave:

Identidade grapiúna, Cacau,

Símbolo, Região cacaueira

Keywords:

Grapiúna identity, Cocoa Symbol, Cocoa region

ISSN: 2236-4994 DOI: 10.5902/2236499428182 
"Há todos os tons amarelos na tranquilidade da manhã nas roças de cacau. E, quando corre uma leve brisa, todo aquele mar de amarelo se balança, as tonalidades se confundem, criam um amarelo novo, o amarelo das roças de cacau, ah! o mais belo do mundo!, um amarelo como só os grapiúnas veem nos dias de verão do paradeiro. Não há palavras para descrevê-lo, não há imagem para compará-lo, um amarelo sem comparação, o amarelo das roças de cacau!" (Jorge Amado).

\section{CONSIDERAÇÕES INICIAIS}

$\mathrm{O}$ estudo da identidade tem ganhado corpo nas diferentes ciências sociais, sendo considerado um tema multidisciplinar e complexo, que perpassa os processos psicológicos, cognitivos e sociais. A identidade é tomada como uma construção social a partir de atributos culturais que são fontes de significados para o indivíduo ou grupo social.

As identidades não são fixas, estão em constante processo de (re) construção a partir "das relações pelas quais somos representados ou interpelados nos sistemas culturais que nos rodeiam" (HALL, 1997, p. 13). Assim, na construção das identidades, são levados em consideração diversos fatores da sociedade, tais como suas crenças e costumes, modos de ser, histórias instituídas ou vividas, objetos culturais como arte, literatura, música. Sendo assim, na constituição das identidades são tomados aspectos que permitem aos indivíduos ou grupos sociais se identificarem com determinado sistema cultural, desenvolvendo assim a ideia de pertença.

Neste artigo, nos propomos a fazer uma breve análise da construção da identidade grapiúna, identidade da região cacaueira do sul da Bahia no início do plantio do cacau no final do século XIX e início do século XX, a partir do romance Terras do Sem Fim do literato baiano Jorge Amado. Nesse sentido, com este artigo objetivamos buscar na obra supracitada elementos que, segundo Jorge Amado, seriam característicos desse povo que vivia direta ou indiretamente sob a influência do cacau.

Como metodologia, utilizamos a pesquisa bibliográfica a partir da análise do romance em questão embasando-a com textos de importantes autores que estudam o tema da identidade. O texto de Penna (1992) foi utilizado enquanto recurso metodológico, sendo correlacionadas as hipóteses que a autora levanta sobre o que faz ser nordestino com algumas partes do romance em que Jorge Amado apresenta- -nos alguns aspectos da identidade grapiúna, afim de melhor compreender as nuances desta identidade.

O romance Terras do Sem Fim narra a sangrenta luta pelas terras do Sequeiro Grande entre duas poderosas famílias de cacauicultores do sul da Bahia e nos oferece elementos importantes para compreender a formação da região cacaueira, tendo o cacau como símbolo máximo da economia e da cultura dessa porção do espaço baiano.

$\mathrm{O}$ artigo foi dividido em duas partes, sendo que, na primeira discutimos o conceito de identidade e sua construção, fundamentados em textos de diversos autores, destacando a identidade grapiúna como uma construção baseada no encontro de diferentes sistemas culturais. $\mathrm{Na}$ segunda parte destacamos alguns elementos presentes no romance em estudo que seriam, segundo Jorge Amado, característicos da chamada identidade grapiúna.

\section{A IDENTIDADE GRAPIÚNA: UMA CONS- TRUÇÃO HÍBRIDA SOB O SIGNO DO CACAU}

O sul da Bahia experimentou na última década do século XIX e, principalmente nas primeiras décadas do século XX, um grande surto de crescimento econômico a partir do plantio e comercialização do cacau. O cacau, encontrando nessa porção do espaço geográfico condições naturais ideais para seu desenvolvimento: solos de alta fertilidade, temperatura elevada, pluviosidade alta e bem distribuída ao longo do ano, foi capaz de atrair um grande contingente populacional, reunindo em um mesmo espaço uma grande diversidade de sujeitos com o mesmo objetivo: produzir riquezas a partir do que Jorge Amado preferia chamar de ouro, "esse ouro que nasce nas terras de Ilhéus, da árvore do cacau" (AMADO, 2001, p. 15).

Em busca desse "ouro", fruto do cacaueiro, os sertanejos deixavam suas terras, fugiam da seca do sertão baiano, cearense, sergipano, para trabalharem nas roças de cacau, sempre sonhando em adquirir seu próprio pedaço de terra e plantar cacau. Vinha gente também de Salvador e de outras partes do país e até mesmo do exterior: sírios, turcos e árabes principalmente. Eram sujeitos diversos. Eram trabalhadores para as roças de cacau já que essa monocultura não mecanizada exigia muita mão de obra, tanto para o plantio quanto para a colheita; eram prostitutas em busca do afamado dinheiro dos coronéis do cacau, 
fama que, segundo Amado, corria mundo; eram advogados, um tipo social muito importante na região cacaueira da Bahia na época da conquista da terra, pois eram responsáveis por expandir os domínios dos coronéis através de falsificação de títulos de terra, o caxixe, na literatura amadiana; iam também jogadores com o intuito de, através do manejo hábil das cartas, ganhar o dinheiro dos coronéis que possuíam fama de rudes e de pouca instrução.

Em função da cultura do cacau, a região sul-baiana foi sendo paulatinamente povoada por diferentes tipos sociais que trouxeram de onde vieram suas experiências, seus dramas, seus hábitos e costumes e se mesclaram formando a região cacaueira da Bahia. Essas mesclas culturais foram capazes de fornecer a essa região um perfil próprio e singularizá-la de tal forma que criou uma identidade regional, a identidade grapiúna. Para Oliveira (2013) a formação sociocultural da região cacaueira da Bahia pode ser classificada como uma formação híbrida, pois ela se originou a partir de estruturas socioculturais que antes existiam separadas, e se combinaram, formando uma nova estrutura sociocultural que é a "civilização grapiúna" (p. 35). Com isso, não queremos afirmar, entretanto, que antes do plantio do cacau o sul da Bahia se constituía em um vazio demográfico, sem nenhuma relação identitária, queremos afirmar que a configuração socioespacial e cultural denominada de região cacaueira da Bahia, somente foi possível com a cultura do cacau.

De um produto econômico, o cacau passa aos poucos a se constituir também em um símbolo da identidade regional. Um símbolo de poder, riquezas, desgraças, misérias, mortes, paixões, sonhos, desejos. O próprio cacau era uma paixão para os habitantes da região cacaueira, como afirma Jorge Amado, "cacau é a única palavra no sul da Bahia que soa bem. As roças são belas quando carregadas de frutos amarelos" (AMADO, 2000, p. 58).

A força do cacau como um símbolo regional é tamanha que surge em volta dele uma Literatura do Cacau, emergindo grandes nomes da literatura brasileira como Jorge Amado e Adonias Filho. Porém, muitos outros escritores e poetas se dedicaram ao cacau enquanto tema de seus escritos, ajudando a construir, representar e divulgar a identidade grapiúna, elencando símbolos e elementos dessa identidade, tais como, Cyro de Matos, Euclides Neto, Sosígenes Costa, James Amado.
Castells (1999) entende a identidade como fonte de significado e experiência de um povo. Para ele, a identidade é "o processo de construção de significado com base em um atributo cultural, ou ainda um conjunto de atributos culturais inter-relacionados, o (s) qual (ais) prevalece (m) sobre outras fontes de significado" (p. 22). Nesse sentido, para o autor, as identidades são fontes de significado para os próprios sujeitos, por eles originadas, e construídas por meio de um processo de individuação. Mesmo quando as identidades são construídas por instituições dominantes, é preciso que os sujeitos as internalizem, construindo assim seu significado a partir dessa internalização.

Em Santos (2002) a identidade já é compreendida como o sentimento de pertencimento, "pertencer àquilo que nos pertence" (p. 10) e está diretamente relacionada à produção e atividade exercidas pelo indivíduo; enquanto Bauman (2006, p. 108-109) afirma que a identidade é segurança que os indivíduos e grupos estabelecem em seus territórios político-administrativos constituídos durante a modernidade.

No que tange à construção da identidade, Castells (1999) afirma que toda identidade é construída. Para ele, a principal questão diz respeito a como, a partir de quê, por quem, e para quê as identidades são construídas. Afirma também que

A construção de identidades vale-se da matéria-prima fornecida pela história, geografia, biologia, instituições produtivas, pela memória coletiva e por fantasias pessoais, pelos aparatos de poder e revelações de cunho religioso. Porém, todos esses materiais são processados pelos indivíduos, grupos sociais e sociedades, que reorganizam seu significado em função de tendências sociais e projetos culturais enraizados em sua estrutura social, bem como em sua visão de tempo/espaço (CASTELLS, 1999, p. 23).

No texto de Da Matta (2000) também encontramos essa noção de que cada sociedade ou grupo social se organiza de forma diferente, e, diferente também é o modo como organizam a economia, as instituições sociais, a cultura, construindo, assim, suas identidades. Dessa forma, o autor afirma que

Tanto os homens como as sociedades se definem por seus estilos, seus modos de fazer as coisas. Se a condição humana determina que todos os homens devem comer, dormir, trabalhar reproduzir-se e rezar, essa determinação não chega ao ponto de especificar também que comida ingerir, de que modo produzir, com que mulher (ou homem) acasalar-se e para quantos deuses ou espíritos rezar. É precisamente aqui, nessa espécie de zona inde- 
terminada, mas necessária, que nascem as diferenças e, nelas, os estilos, os modos de ser e estar, os "jeitos" de cada qual. [...] Trata-se, sempre, da questão da identidade. De saber quem somos e como somos; de saber por que somos. Sobretudo quando nos damos conta que o homem se distingue dos animais por ter a capacidade de se identificar, justificar e singularizar: de saber quem ele é. [...] A construção de uma identidade social, então, como a construção de uma sociedade, é feita de afirmativas e negativas (DAMAT'TA, 2000, p. 15-17).

No caso da identidade grapiúna, mesmo o cacau sendo o ponto central do desenvolvimento econômico, social e cultural do sul da Bahia a partir do final do século XIX, ele sozinho não explica a conformação dessa identidade. O cultivo do cacau desenvolveu-se também em outras partes do mundo como outros países da América Latina e países africanos. Mas a forma como os indivíduos e grupos sociais da região cacaueira da Bahia processaram os elementos naturais, a apropriação das terras para o cultivo, a adaptação e transformação do meio geográfico e mesclaram suas culturas e criaram novos códigos culturais, com certeza foi diferente. Essa região resulta, assim, em uma diferenciação espacial e sociocultural com uma identidade própria, diferenciada.

É nesse sentido que concordamos com Adonias Filho (2007) quando o autor afirma que a uniformidade ecológica, flora, fauna e clima não bastam para justificar a civilização do cacau. Assim, "a estrutura social e a organização econômica - sempre resultantes do cacau - a completam como fornecedoras de normas, convivências e identidades e fins que asseguram regionalmente a integração" (ADONIAS FILHO, 2007, p. 10). Segundo este autor, a saga do cacau fermentou matéria artística e ficcional e concorreu para configurar o que realmente é um complexo de cultura regional, pois "o cacau à proporção que altera a paisagem, a empurrar e diminuir a selva, a abrir fazendas, estabelecer um sistema de comércio conforma culturalmente uma região" (p.10).

Woodward (2014) chama a atenção para a questão da diferença na construção das identidades. Para a autora, as identidades são fabricadas a partir da diferença, e "essa marcação da diferença ocorre tanto por meio de sistemas simbólicos de representação quanto por meio de formas de exclusão social" (p. 40, grifos no original). Seguindo essa mesma linha de raciocínio, Silva (2014) assinala que a identidade depende da diferença e a diferença depende da identidade, sendo mutuamente determinadas. A identidade e a diferença são criações sociais e culturais.

A afirmação da identidade e a marcação da diferença implicam sempre em ações de incluir e excluir. Ou seja, ao dividir o mundo social em "nós" e "eles" estamos assim classificando. E a classificação é central na vida social e pode ser entendida como um ato de significação pelo qual dividimos o mundo em grupos, classes. A identidade e a diferença estão estreitamente relacionadas às formas pelas quais a sociedade produz e utiliza as classificações do mundo social. As classificações são sempre feitas a partir do ponto de vista da identidade. Dividir e classificar significa também hierarquizar, ou seja, significa eleger um superior e um inferior. Sendo assim, os sentimentos de pertencimento ou não pertencimento a determinados grupos ou culturas, são tomados como forma de exclusão concreta ou metafórica dos sujeitos com os quais não se produz identificação, ou seja, os sujeitos diferentes (AZEVEDO, 2007; SILVA, 2014). Mais adiante, destacaremos como Jorge Amado trabalhou esta questão no romance que estamos analisando.

A análise do romance que se segue nos fornece uma ideia de como Jorge Amado representou e contribuiu, a partir das suas narrativas, para a formação da identidade grapiúna, sendo que o cacau é o grande responsável por reunir em uma porção do espaço baiano, grande diversidade de sujeitos sociais que, a partir de interações culturais, darão singularidade a esse espaço. Nesse sentido, ao representar a identidade grapiúna, Jorge Amado também influencia o imaginário social dos habitantes da região cacaueira da Bahia que, ao entrarem em contato com suas narrativas, se reconhecem e se (re) afirmam enquanto grapiúnas.

\section{A IDENTIDADE GRAPIÚNA: ELEMENTOS DE DIFERENCIAÇÃO, CLASSIFICAÇÃO E PERTENCIMENTO PRESENTES NA NARRA- TIVA AMADIANA}

No romance Terras do Sem Fim, publicado em 1943, Jorge Amado, ao narrar a saga da conquista da terra para o plantio do cacau no sul da Bahia em fins do século XIX e início do século XX, nos apresenta os sujeitos que compõem o painel humano da chamada região cacaueira da Bahia: os coronéis, os jagunços, os trabalhadores das roças de cacau. Apresenta-nos também os seus costumes, crenças, hábitos, lendas, mitos. 
O cacau aparece como o signo máximo da região, e, era ele a força motriz dessa porção do espaço baiano, tanto que a singulariza e a identifica mundialmente como a região cacaueira da Bahia até a atualidade.

$\mathrm{Na}$ trama amadiana, o próprio cacau, de símbolo econômico passa a símbolo da identidade regional. Todos na região viviam direta ou indiretamente em função do "fruto de ouro" e que, segundo Amado "valia mais que o próprio ouro" (AMADO, 2001, p. 13). Aqui, percebe-se que o cacau, ao ser comparado ao ouro, não tinha apenas valor financeiro, mas valor simbólico também. Não havia, na percepção da ficção amadiana, um grapiúna que não tivesse sua vida ligada ao cacau: amando-o ou odiando-o, ele estava presente em suas vidas. Prendia-os àquela terra como o visgo do cacau mole preso aos pés dos trabalhadores das roças. Enchia o coração dos homens de sonhos, mas era também o grande provedor das tragédias humanas daquela gente que dependia dele.

Um dos elementos que diferencia e caracteriza os grapiúnas, na visão de Jorge Amado, no romance em questão, é o destemor, a valentia, o desapego à própria vida. Isso é justificado, segundo o romancista, pela extrema violência com a qual ocorreu o processo de desbravamento das terras do sul da Bahia para o plantio do cacau. Para Jorge Amado, no tempo da conquista da terra, "as cruzes demarcavam os caminhos do progresso da região, os cadáveres estrumavam os cacauais" (AMADO, 1982, p. 13). Nas Terras do Sem Fim, as "terras semibárbaras de São Jorge dos Ilhéus" (AMADO, 2001, p. 9), não se admite a covardia, o destemor é uma característica do homem grapiúna e essa característica é um dos elementos que singulariza e identifica os grapiúnas, como pode ser observado a partir do excerto abaixo:

O coronel gordo espantava o caixeiro-viajante narrando um barulho que tivera numa pensão de mulheres na Bahia [Salvador]. Uns malandros fizeram-se de besta, tinham querido correr em cima dele por causa de uma mulatinha. Ele puxou o parabélum ${ }^{1}$ e bastou gritar: vem com coragem que eu sou é de Ilhéus... - para que os malandros recuassem acovardados.

O viajante se assombrava com a coragem do coronel:

- O senhor foi macho pra burro! (AMADO, 2001, p. 9-10).

A covardia era algo desprezível entre os grapiúnas. Uma terra onde somente se falava em cacau e mortes, cujo contexto social do seu desbravamento para o plantio do cacau foi de extrema violência e desmandos, onde os jagunços recebiam ordens dos coronéis para esperar homens na estrada, escondidos atrás de uma árvore para tirar-lhes a vida, não poderia ser ocupada por sujeitos covardes. Nesse sentido,

A única coisa que realmente desmoralizava alguém por completo, naquela zona, de Ferradas a Ilhéus, era a covardia. Homem com fama de covarde era homem sem futuro nessas estradas e nesses povoados. Se alguma virtude era exigida a um homem para tentar a vida no sul da Bahia, na época da conquista da terra, essa virtude era a coragem pessoal. Como se aventurar alguém entre jagunços e conquistadores de terra, entre advogados sem escrúpulos e assassinos sem remorso, se não levasse consigo a despreocupação da vida e da morte?

Homem que apanhava sem reagir, que fugia de barulho, que não tinha uma história de valentia para contar, não era levado a sério entre os grapiúnas (AMADO, 2001, p. 154).

Essa questão do destemor como uma característica da identidade dos grapiúnas na época da conquista da terra para o plantio do cacau (final do século XIX e início do século XX), é tão levada a sério por Jorge Amado que neste romance, ele estende essa característica também às mulheres na personagem de Don'Ana Badaró. Em uma sociedade extremamente machista e patriarcal na qual o papel da mulher era secundário, Don'Ana Badaró, que ocupava uma posição privilegiada por ser filha do coronel Sinhô Badaró, um dos homens mais ricos da terra, não se comportava como as mulheres da sua época e da sua posição social. Não se importava com joias, roupas caras ou festas, gostava mesmo era das roças de cacau e não apenas dos lucros que essa monocultura the rendia. Sabia manejar armas, participava das decisões dos homens da família (seu pai e seu tio) para ampliar os domínios dos Badarós.

$\mathrm{Na}$ narrativa do romance em questão, quando o advogado do coronel Horácio da Silveira, o grande rival dos Badarós na disputa pelas terras do Sequeiro Grande, realizou um grande caxixe ${ }^{2}$, registrando em cartório as terras como pertencendo a Horácio, Don'Ana Badaró ao saber da notícia, estando sozinha em casa, não hesitou em chamar um dos aliados do seu pai e mandar colocar fogo no cartório, incendiando todos os documentos que comprovavam o registro das terras. Continuando a narrar as proezas destemidas de Don'Ana Badaró, Jorge Amado fala da invasão da fazenda dos Badarós pelo coronel Horácio da Silveira e sua gente, quando da intensificação das lutas pelas terras do Sequeiro Grande. Após matar a maioria dos homens dos Badarós e ferir gravemente o coronel Sinhô Badaró, Horácio da Silveira avança com seus homens em direção à casa-grande para incendiá-la, como narra Jorge Amado no excerto a seguir: 
[...] Os cabras $^{3}$ de Horácio, com Braz à frente, entravam no terreiro da casa-grande dos Badarós. [...] Havia um silêncio completo na noite sem lua. [...] Um deles, obedecendo a uma ordem, riscou um fósforo para acender um fifó ${ }^{4}$. O tiro veio de dentro da casa, raspou na luz, não matou o homem por um milagre. Os outros se atiraram no chão, foram entrando de rastros na casa. De dentro alguém atirava, procurando visar Horácio no meio dos capangas. Braz avisou ao coronel:

-É mais de um...

Entraram na casa, as armas na mão, os olhos atentos, procurando. [...] Os tiros haviam cessado, Braz comentou:

- Terminou a munição...

Braz ia na frente, dois cabras a seu lado, Horácio vinha logo atrás. Só restava o sótão. Foram subindo a escada estreita, Braz abriu a porta com um pontapé. Don'Ana Badaró atirou, um cabra caiu. E como era a última bala que lhe restava, ela jogou o revólver para o lado de Horácio e disse com desprezo:

- Agora mande me matar, assassino..

E deu um passo à frente. Braz abria a boca num espanto. Ele tinha visto quando ela passara com Olga e Raimunda, guardada por uns poucos homens, fugindo. [...] Como diabo tinha voltado? Don'Ana deu outro passo à frente, seu vulto encheu a pequena porta do sótão.

Horácio saiu para um lado da escada:

- Vá embora moça... Eu não mato mulher...

Don'Ana baixou a escada, atravessou a sala, [...] saiu para o terreiro, os homens a fitavam mudos. Um murmurou:

- Diabo de mulher corajosa! (AMADO, 2001, p. 282-283).

O destemor da personagem Don'Ana a fez abandonar o grupo de mulheres que corriam do conflito e retornar para a sua casa para honrar o nome da sua família e defender seu patrimônio. Nascida e criada naquela terra sob o barulho dos tiros, com os costumes daquela gente rude, ela adquiriu o gosto pelos hábitos que estariam, na cultura daquela terra, mais destinados aos homens.

Mas Jorge Amado apresenta-nos também uma exceção. Com uma narrativa irreverente, nos apresenta o doutor Jessé, cuja covardia era tamanha que servia de medida para a dos outros:

A covardia do dr. Jessé era proverbial e quando queriam medir a de outro a medida era sempre o médico:

- É quase tão medroso quanto o doutor Jessé..

Ou então:

- É tão covarde que nem parente do doutor Jessé... (AMADO, 2001 p. 154-155).

E para ilustrar a tamanha covardia do doutor Jessé, o romancista narra dois fatos ilustrativos e representativos dessa característica desse personagem:

Num barulho de proporções que houvera em Tabocas entre a gente de Horácio e a gente dos Badarós, por exemplo, se contava que o doutor Jessé havia enveredado por uma casa de mulheres da vida e fora encontrado escondido debaixo da cama. De outra feita, ele discursava durante um meeting de propaganda eleitoral [...]. Viera da Bahia [Salvador], como candidato a deputado da oposição por aquela zona, um rapaz que começava sua carreira política. O rapaz viera fazer sua propaganda com muito medo. Lhe haviam contado brabezas dessa terra e ele temia receber um tiro ou uma punhalada. [...] Primeiro falou dr. Rui, [...] depois discursou o dr. Jessé [...] e por fim, chegou a vez do visitante [...]. Tossiu para chamar a atenção, o silêncio era completo, começou:

- Senhoras, senhores e senhoritas... Eu...

Não pôde dizer mais nada. Como não havia nem senhoras nem senhoritas um gaiato gritou:

- Senhorita é a mãe..

Riram, outros pediam silêncio. [...] Os cabras dos Badarós se aproveitaram do zunzum para começar o tiroteio, logo respondido pelos homens de Horácio. Dizem que então quando o moço candidato quis se meter debaixo da tribuna para fugir às balas que se cruzavam, já a encontrara ocupada pelo doutor Jessé, que não só não lhe fez lugar, como disse:

- Se o senhor não quer ficar desmoralizado volte para seu lugar. Aqui só eu tenho o direito de me esconder porque sou covarde de tradição... (AMADO, 2001, p. 155-156).

Mas mesmo sendo um covarde de tradição, o doutor Jessé era um homem respeitado entre os grapiúnas, pois sendo "médico em Tabocas, vereador em Ilhéus, eleito por Horácio, sendo um dos chefes políticos da oposição, fora a única pessoa que se sustentara no conceito público apesar de todos o saberem medroso" (AMADO, 2001, p. 154). Nesse caso, o doutor Jessé vale-se dos seus papéis sociais (médico e político) para encaixar-se entre os grapiúnas e por eles ser reconhecido como pertencente àquela comunidade.

Anteriormente, nos posicionamos, com respaldo nas ideias de Silva (2014) e Woodward (2014) que afirmam que a identidade se constrói a partir da diferença e que a marcação da identidade e da diferença implica em incluir e excluir, em construir oposições binárias como, por exemplo, "nós" e "eles". No caso do nosso objeto de estudo, a identidade grapiúna, a partir do olhar ficcional de Jorge Amado, o "nós", ou seja, os grapiúnas, são os destemidos, aqueles que desprezam a covardia e, sendo assim, os covardes não são admitidos na comunidade, sendo, portanto o "eles". A exceção no romance Terras do Sem Fim é representada no personagem do doutor Jessé que a partir dos importantes papéis sociais que desempenha naquela comunidade, consegue aceitação, porém, sob pena de ser tomado como objeto de zombaria entre os grapiúnas. Assim, concordamos com Cruz (2007) quando este afirma que,

É nesse jogo relacional de classificação/distinção/identificação que a identidade é construída e configurada ao mesmo tempo como inclusão e exclusão: ela identifica o 
grupo (membros do grupo que são idênticos) e o distingue dos outros grupos (cujos membros são diferentes dos primeiros sob um certo ponto de vista). Nessa perspectiva, a identidade aparece como categorização da distinção nós/eles, baseada na diferença (CRUZ, 2007, p. 18).

Dessa conquista violenta da terra para o plantio do cacau é que o povo grapiúna se constitui enquanto um povo destemido, segundo Jorge Amado, e a partir dessa conquista violenta é que também surge outro elemento muito importante para se sustentar na comunidade: o porte de armas. Dificilmente se encontrava um grapiúna sem portar armas, independente do papel social que desempenhava, a arma era mais que um símbolo do destemor, era uma necessidade de sobrevivência, como pode ser observado nos fragmentos do romance Terras do Sem Fim, a seguir:

[...] Mais atrás, ao lado de Horácio [...], vinha, baixo e troncudo, o rosto cortado por um longo talho de facão, compadre Braz, dono de uma roça junto das matas de Sequeiro Grande, respeitado como ele só na zona do cacau. Trazia uma repetição na frente da sela e sobre ela descansava a mão que segurava a rédea. $\mathrm{E}$ vinham cabras e tropeiros, a repetição no ombro, o revólver no cinto.

[...] Citava-se o caso do padre Paiva, que levava sob a batina um revólver e não se perturbava se acontecia um barulho perto dele. (AMADO, 2001 p. 140; 199).

E mesmo quando era proibida pelo poder instituído, essa proibição não era impedimento para o uso de armas nas ruas.

Existia outra ordenança municipal, que proibia o porte de armas. Mas muito poucas pessoas sabiam que ela existia e, mesmo aqueles poucos que o sabiam, não pensavam em respeitá-la. Os homens passavam, calçados de botas ou de botinas de couro grosso, a calça cáqui, o paletó de casimira, e por baixo deste o revólver. Homens de repetição a tiracolo atravessavam a cidade sob a indiferença dos moradores (AMADO, 2001, p. 200).

Penna (1992), estudando a identidade nordestina, faz uso de quatro hipóteses na tentativa de responder à questão: o que faz ser nordestino? A autora elenca inicialmente três hipóteses que segundo ela tomam a identidade numa perspectiva empírica, diretamente decorrente de algum fato observável:

1. a naturalidade: a identidade nordestina é dada objetivamente pelo local de nascimento, ou seja, se este pertence à região Nordeste, automaticamente o indivíduo é nordestino;

2. a vivência: a experiência de vida dentro das fronteiras da região é que faz ser nordestino;

3. a cultura: as práticas culturais indicam a identidade nordestina (PENNA, 1992, p. 50-51).
A quarta hipótese que Penna (1992) cita é a autoatribuição, ou seja, uma hipótese a partir da qual o indivíduo se reconhece, se define, se classifica, identificando-se assim com determinado grupo social ao mesmo tempo em que diferencia-se de outros. Na hipótese da autoatribuição, "o indivíduo é nordestino se se reconhece como tal” (PENNA, 1992, p. 51).

Avançando um pouco mais no entendimento da identidade grapiúna a partir do romance amadiano Terras do Sem Fim, tomamos o texto de Penna (1992) como recurso metodológico a fim de confrontar as hipóteses supracitadas com alguns trechos do romance em questão.

No tocante à primeira hipótese, a naturalidade, constatamos que ela sozinha não responde pela identidade grapiúna, pois como já tratamos acima, no final do século XIX e início do século XX muitos migrantes se dirigiram para o sul da Bahia em busca do eldorado que o cacau representava. Como no romance em estudo, Amado (2001) se refere justamente a esse início da formação da região cacaueira da Bahia, ele nos esclarece também que a identidade dessa gente, a identidade grapiúna, é, portanto, o resultado do encontro de diferentes sistemas socioculturais. Assim, quando se refere à cidade de Ilhéus, (a mais importante cidade do sul da Bahia no início do século XX), por exemplo, Jorge Amado afirma que "existiam poucos ilheenses de nascimento que já tivessem importância na vida da cidade. Quase todos os fazendeiros, médicos, advogados, agrônomos, políticos, jornalistas, mestres de obra eram gente vinda de fora, de outros estados" (AMADO, 2001, p. 200 201).

Embora nascidos em outros estados ou em outras regiões da Bahia, "amavam estranhamente aquela terra venturosa e rica" (AMADO, 2001, p. 201). Aqui, a vivência nos limites da região cacaueira da Bahia é um componente importante para se sentir um grapiúna. Aquela terra representava uma nova vida, longe das prolongadas secas do sertão. Um sonho de alcançar a riqueza para muitos que se aventuravam por aquela terra próspera. $E$ nessa vivência na região, adquirem também as práticas culturais que encontram na nova terra (o cacau como um símbolo da terra, o destemor, o porte de armas) mesclando-as com aquelas que trouxeram de outros sistemas culturais. Nesse ponto, podemos pensar também no lu- 
gar enquanto gerador de identidade(s), pois o lugar carrega forte conotação de afetividade e segurança, significando para o ser humano, "a base para assentar o Ser" (DARDEL, 2011, p. 29), consubstanciado a partir da experiência humana em seu cotidiano (CHAVEIRO, 2014; RELPH, 2014).

Para Penna (1992), com a qual concordamos, a análise da identidade não deve se valer apenas de dados objetivos, fatos observáveis ou da materialidade (local de nascimento, tempo de vivência, práticas culturais), "torna-se prioritário que o pesquisador busque captar o modo como a identidade é simbolicamente representada, em situações determinadas, ou, mais especificamente a forma de autorreconhecimento" (PENNA, 1992, p. 74). Essa última hipótese pode ser exemplificada, no romance Terras do Sem Fim, com o excerto a seguir:

Todos se diziam grapiúnas e, quando estavam na Bahia [Salvador], em toda parte eram facilmente reconhecíveis pelo orgulho com que falavam.

- Aquele é um ilheense... - diziam.

Nos cabarés e nas casas de negócios da capital eles arrotavam valentia e riqueza, gastando dinheiro, comprando do bom e do melhor, pagando sem discutir preços, topando barulhos sem discutir o porquê. Nas casas de rameiras, na Bahia [Salvador], eram respeitados, temidos e ansiosamente esperados (AMADO, 2001, p. 201).

No fragmento acima, além do autorreconhecimento, há, também, o reconhecimento externo a partir dos indicadores objetivos, observáveis. Para Penna (1992), na alter-atribuição da identidade, os hábitos, ações, bens de cada grupo ou indivíduo, são objetos de representações mentais dos outros. Servem a estes, portanto, como referenciais para situar socialmente, para designar certa classe, para identificar.

Sendo assim, nesta direção de reconhecimento que vem "de fora", ganham grande importância as práticas sociais e culturais, enquanto manifestações que podem ser interpretadas e valoradas diferentemente pelo próprio grupo e pelos vários setores com que entra em contato, pois tais signos são apreendidos pelos outros conforme os esquemas de percepção e apreciação de que dispõem (PENNA, 1992, p. 75).

Os indicadores observáveis não respondem sozinhos pelo reconhecimento da identidade, porém, eles não podem ser subtraídos da análise do jogo de constituição das identidades, pois servem de base para a alter-atribuição. Por outro lado, não se pode tomar a identidade apenas pela autoatribuição, ou seja, a partir da subjetividade. Cruz (2007) e Penna (1992) concordam que, no estudo da identidade, é preciso apreender simultaneamente os níveis objetivo e subjetivo, para que um não se reduza ao outro. Para Cruz (2007) é importante superar as posições dualistas como: material/simbólico, objetivo/subjetivo. Para este autor,

A identidade é construída subjetivamente, baseada nas representações, nos discursos, nos sistemas de classificações simbólicas, embora não seja algo puramente subjetivo e não se restrinja à "textualidade" e ao "simbólico". Ela não é uma construção puramente imaginária que despreza a realidade material e objetiva das experiências e das práticas sociais como muitos afirmam, e nem tampouco é algo materialmente dado, objetivo, uma essência imutável, fixa e definitiva (CRUZ, 2007, p. 18).

Confirmando a premissa de Hall (1997), de que a identidade é definida historicamente e não biologicamente e que o sujeito assume diferentes identidades em diferentes momentos ao entrar em contato com diferentes sistemas culturais, no romance Terras do Sem Fim, ilustra-se com o personagem do doutor Virgilio. Nascido e criado na capital do estado, Salvador, jovem advogado de familia influente, sendo convidado pelo coronel Horácio da Silveira para ser seu advogado e do partido de oposição ao governo do estado, passa a morar em Ilhéus, município de grande ascensão econômica da região cacaueira no início do século XX.

Ao entrar em contato com a cultura da região cacaueira, na qual a violência reinava, Virgílio vê-se obrigado a comungar das práticas locais. Em um baile, dançava com sua ex-amante Margot, e ao final da dança o coronel Juca Badaró retira a moça dos seus braços. Para Virgilio, o fato foi apenas um incidente, mas o coronel Horácio da Silveira (inimigo dos Badarós), procurando um motivo, por menor que fosse, para matar Juca, tenta convencer o jovem advogado de que o fato era grave, e que ele deveria mandar matar o coronel, sob pena de ficar desmoralizado em uma terra em que a honra de um homem se lava com sangue:

[...] - O senhor não se dá conta doutor, que se o senhor não toma uma atitude, ninguém mais, me desculpe dizer, vai levar o senhor a sério nessas terras...

- Mas por quê?

- Juca Badaró anda dizendo a Deus e ao mundo que arrancou uma mulher dos braços do senhor, que the insultou e o senhor não reagiu. Que o senhor, me desculpe repetir, é um cagão. [...] não quero que o senhor fique desmoralizado por aqui, com fama de covarde... por isso estou the falando.

- O que é que o senhor acha que eu devo fazer? 
Horácio jogou no chão o fósforo que lhe queimava o dedo, a ponta de cigarro continuava apagada, pequena no lábio grosso:

- Tenho um cabra aí, homem de confiança. Na quinta-feira Juca Badaró vai subir para a fazenda, estou informado. Com cinquenta mil-réis o senhor resolve o assunto (AMADO, 2001, p. 244-245).

Ao lidar com aquele povo, Virgílio já tinha notícias dos seus costumes, convivia com eles, embora sua formação e vivência fora daqueles limites the permitissem avaliar aquelas práticas culturais como primitivas. Porém, naquele momento, vê-se obrigado a não somente coexistir com aqueles costumes, como também a praticá-los. Seus sentimentos identitários entram em conflito, pois com base em sua carga cultural anteriormente estabelecida, o ato de matar alguém por um motivo torpe não é o correto, porém para se manter naquela terra, era preciso fazê-lo:

\footnotetext{
Virgílio sentou-se:

- Mas isso não é coragem, coronel. Mandar um jagunço matar um homem, a sangue-frio, isso não é coragem... Se eu me encontrar com Juca na rua, meter a mão no rosto dele, está certo... Mas mandar um cabra dar um tiro? Para mim isso não é coragem...

- Aqui é assim, doutor. E se o senhor pensa em fazer carreira aqui, deixe que eu chame o cabra... Senão não tem jeito. O senhor pode ser o melhor advogado do mundo, ninguém vai procurar o senhor...

[...] Virgílio sentou-se de novo. Refletia. Nunca esperara aquilo. Sabia que Horácio tinha razão. Naquela terra mandar matar era coragem, fazia um homem respeitado (AMADO, 2001, p. 245).
}

Para Hall (1997), existem dentro de nós identidades contraditórias, empurrando em diferentes direções, e assim nossas identidades estão sendo continuamente deslocadas, e "se sentimos que temos uma identidade unificada desde o nascimento até a morte é apenas porque construímos uma cômoda estória sobre nós mesmos ou uma confortadora 'narrativa do eu"' (HALL, 1997, p. 13-14).

Almeida (2005); Cruz (2007); Giménez (2000); Pollice (2010) também entendem a identidade como uma dinâmica, ou seja, muda no tempo e no espaço, não sendo, portanto, uma essência, não é um fato fixo, estável, permanente nem completamente coerente. A identidade é instável, contraditória, inacabada e contingente. Nesse sentido, Giménez (2000) enfatiza, "la identidad es creatividad permanente y exploración continua, y en cuanto tal implica una dialéctica de continuidad y cambio" (GIMÉNEZ, 2000, p. 117).
Quando Virgilio admite que era preciso, ele mesmo, ter que mandar matar um homem para obter o respeito e a consideração dos grapiúnas, percebe que sua identidade não é fixa, está em transformação e ele também está se tornando um grapiúna, mesmo não abandonando por completo seus referenciais identitários anteriormente estabelecidos. E só naquele momento, começou a refletir sobre os costumes daquela gente. Como era fácil para os coronéis, os advogados que haviam envelhecido naquela terra, mandar um homem armar uma tocaia no meio da noite para matar outro. Mas não era fácil para ele, educado noutra terra, noutros costumes, com outros sentimentos. Ali,

Mandavam matar como mandavam podar uma roça ou tirar uma certidão de idade no cartório. Sim, para eles era fácil e Virgílio nunca se havia demorado em considerar o estranho desse fato. Só agora olhava com outros olhos para estes homens rudes das fazendas, esses advogados manhosos da cidade e dos povoados, que, calmamente, mandavam cabras esperar inimigos na estrada, por trás de uma árvore. Sua ambição, primeiro, o amor de Ester e o desejo de partir com ela, depois, fizeram com que ele nunca se lembrasse de refletir sobre o terrível daqueles dramas que eram o quotidiano daquela terra. Fora preciso que ele se visse obrigado a ter que mandar, ele também, matar um homem, para sentir a desgraça daquilo tudo, o terrível daqueles fatos, o quanto aquela terra pesava sobre os homens (AMADO, 2001, p. 249).

E para ilustrar a força que o cacau exercia sobre aquela gente, seja pelo amor ou pelo ódio, seja pela vida ou pela morte, pela riqueza ou pela pobreza, Jorge Amado trabalha com a metáfora do visgo do cacau que ele utiliza não somente em Terras do Sem Fim, como em outros romances como Cacau e São Jorge dos Ilhéus. Ao pisar os caroços de cacau para retirar o mel e assim secar mais rapidamente, os trabalhadores ficavam com o visgo do cacau preso aos pés e com o tempo criava uma casca grossa que já fazia parte deles.

E eles todos, os trabalhadores, jagunços, coronéis, advogados, médicos, comerciantes e exportadores tinham o visgo do cacau preso na alma, lá dentro, no mais profundo do coração... Não havia educação, cultura e sentimento que lavassem. Cacau era dinheiro, era poder, era a vida toda, estava dentro deles, não apenas plantado sobre a terra negra e poderosa de seiva. Nascia dentro de cada um, lançava sobre cada coração uma sombra má, apagava os sentimentos bons. Virgílio não estava com ódio nem de Horácio, nem de Maneca Dantas [...]. Tinha ódio era do cacau... Se revoltava porque se sentia dominado, porque não tivera forças para dizer não e deixar que Horácio sozinho fosse responsável pela morte de Juca. Não sabia mesmo como aquela terra, aqueles costumes, tudo que nascia junto com o cacau, se haviam apossado dele (AMADO, 2001, p. 249). 
Ao refletir sobre tudo isso, Virgilio percebe que mesmo discordando daquelas práticas culturais, ele, ao praticá-las, já é reconhecido e se autorreconhece enquanto um grapiúna, e assim sendo, "não adianta mais pensar em fugir, agora seus pés estão presos ao visgo daquela terra, visgo de cacau mole, visgo de sangue também. [...] Agora ele era também um grapiúna, definitivamente um grapiúna" (AMADO, 2001, p. 251). E quando avisado pelo coronel Maneca Dantas que o coronel Horácio havia descoberto o caso que Virgilio teve com sua esposa Ester, e que ele iria matá-lo, o advogado recusou o conselho do amigo de fugir, e caminhou para a morte conforme os costumes da terra, conforme a lei do cacau.

\section{CONSIDERAÇÕES FINAIS}

A análise do romance amadiano Terras do Sem Fim, possibilita compreender que a identidade da região cacaueira do sul da Bahia, a identidade grapiúna, se constituiu a partir da mistura de sistemas socioculturais que, ao entrarem em contato, se (re) organizaram e conformaram essa identidade tendo o cacau como símbolo.

Os elementos que, segundo Jorge Amado, são característicos dessa identidade são frutos da forma como a conquista da terra se processou e da junção das diversas características socioculturais que se encontraram no sul da Bahia no final do século XIX e início do século XX e que se constituíram enquanto fonte de significados para esse povo.

Constatamos, com base em diversos autores, que a identidade não é fixa sendo, portanto, uma "celebração móvel" nas palavras de Hall (1997). Dessa forma, mesmo o cacau ainda permanecendo como um símbolo da identidade grapiúna na atualidade, as características apresentadas no romance analisado não respondem completamente por essa identidade hoje, pois os sistemas socioculturais são modificados ao longo do tempo. Porém, essas características apresentadas no romance nos dão uma ideia de como a identidade grapiúna se constituiu e ainda permanece na memória e no imaginário social da região cacaueira da Bahia, a partir das narrativas de Jorge Amado e de outros romancistas, poetas e artistas da referida região.

\section{REFERÊNCIAS}

ALMEIDA, M. G. de. Fronteiras, territórios e territorialidades. Revista da ANPEGE. Ano 2, n. 2. Fortaleza: ANPEGE, 2005. p. 103-114.

AMADO, J. O menino grapiúna. 5 ed. Rio de Janeiro: Record, 1982. $120 \mathrm{p}$.

AMADO, J.. Terras do sem fim. 68. ed. Rio de Janeiro: Record, 2001. 320 p.

AMADO, J.. Cacau. Rio de Janeiro: Record, 2000. 144 p.

AZEVEDO, A. F. Geografias pós coloniais: Contestação e renegociação dos mundos culturais num presente pós colonial. In: PIMENTA, J. R. et al. (Org.). Geografias pós coloniais. Porto: Livraria Figueirinhas, 2007. p. 31-69.

BAUMAN, Z. Modernidad líquida. Tradução: Fondo de Cultura Económica. Buenos Aires, 2006. p. 99-138.

CASTELLS, M. O poder da identidade. Tradução: Klauss Brandini Gerhardt. São Paulo: Paz e terra, 1999. p. 21-92.

CHAVEIRO, E. F. Corporeidade e lugar: elos da produção da existência. In: MARANDOLA, E. Jr. et. al. (Orgs.). Qual é o espaço do lugar? Geografia, epistemologia, fenomenologia. São Paulo: Perspectiva, 2014. p. 249-279.

CRUZ, V. C. Itinerários teóricos sobre a relação entre território e identidade. In: BEZERRA, A. C. A. et. al. (Orgs.). Itinerários geográficos. Niterói: EdUFF, 2007. p. 13-35.

DAMATTA, R. O que faz o brasil, Brasil? Rio de Janeiro: Rocco, 2000. p. 09-20.

DARDEL, E. O homem e a Terra: natureza da realidade geográfica. Tradução: Werther Holzer. São Paulo: Perspectiva, 2011. p. 20-31.

FILHO, A. Sul da Bahia: chão de cacau. 3 ed. Rio de Janeiro: Bertrand Brasil, 2007. 127p.

GIMÉNEZ, G. Territorio, cultura e identidades: La región sociocultural. In: BARBERO, J. M. et. al. (Eds.). Cultura y región. Colombia: Litocamargo, 2000. p. 87-132. 
HALL, S. A identidade cultural na Pós-Modernidade. Tradução: Tomaz Tadeu da Silva e Guacira Lopes Lobo. Rio de Janeiro: DP\&A, 1997. p. 07-23.

MOURA, C. Dicionário da escravidão negra do Brasil. São Paulo: EDUSP, 2003. p. 75.

OLIVEIRA, R. L. de. A palavra e o tempo de Euclides Neto: um garimpeiro da identidade cultural grapiúna. Ilhéus: Editus, 2013. 186 p.

PENNA, M. O que faz ser nordestino: identidades sociais, interesses e o "escândalo" Erundina. São Paulo: Cortez, 1992. p. 49-81.

POLLICE, F. O papel da identidade territorial no desenvolvimento local. Espaço e Cultura, UERJ, RJ, n. 27, p. 7-23, jan-jun, 2010.

RELPH, E. Reflexões sobre a emergência, aspectos e essência de Lugar. In: MARANDOLA, E. Jr. et. al. (Orgs.). Qual é o espaço do lugar? Geografia, epistemologia, fenomenologia. São Paulo: Perspectiva, 2014. p. 17-32.

SANTOS, M. O dinheiro e o território. In: . et. al. que o cabra é quarteirão de mulato com negro, mulato escuro, caboclo escuro. V. Chermont diz tratar-se de mestiço de branco com negra, logo, o mesmo que mulato. Rodolfo Teófilo, afirma que é o produto do cruzamento de índio e de africano, inferior aos elementos que o formam”.

4 - O mesmo que candeeiro

\section{Correspondência dos autores:}

Rita de Cássia Evangelista dos Santos e-mail: cassiacollins@yahoo.com.br

Valéria Cristina Pereira da Silva e-mail:vpcsilva@hotmail.com

Artigo recebido em: 21/09/2017

Revisado pelo autor em: 05/12/2017

Aceito para publicação em: 05/01/2018

SILVA, T. T. da. A produção social da identidade e da diferença. In: (Org.). Identidade e diferença: a perspectiva dos estudos culturais.15 ed. Petrópolis: Vozes, 2014. 07-72.

WOODWARD, K. Identidade e diferença: uma introdução teórica e conceitual. In: SILVA, T. T. da. (Org.). Identidade e diferença: a perspectiva dos estudos culturais. 15 ed. Petrópolis: Vozes, 2014. 07-72.

\section{Notas de Fim:}

1- Certa pistola automática de procedência alemã. (Fonte: Dicionário Michaelis Online).

2- $\mathrm{O}$ equivalente hoje à grilagem de terras, falsificação de título de propriedade.

3- Segundo o Dicionário da escravidão negra do Brasil, (2003) o termo "cabra" é designativo do mestiço de negro e mulato. Porém, não há consenso sobre esse termo: "Macedo Soares diz 